\title{
PLÁSTICOS: O CAMINHO PARA UMA ECONOMIA MAIS CIRCULAR
}

Jéssica Mello Tahim ${ }^{1}$

Thais Muliterno ${ }^{2}$

Recebido em 14/03/2021

Aceito em 07/08/2021

\section{RESUMO}

Por mais que os plásticos tenham surgido como uma solução econômica, por serem mais baratos, flexíveis, versáteis e duráveis, em substituição a outros produtos, tais como o vidro e aço, eles acabaram causando grandes impactos negativos ao ambiente e, consequentemente, à saúde e vida humana, por sua má utilização e gestão indevida dos resíduos plásticos. Diante dessa problemática, a União Europeia formulou e aprovou algumas estratégias, para que referido problema fosse solucionado ou, pelo menos, que seus efeitos sejam mitigados, sem que seja necessária a retirada de todos os produtos plásticos do mercado e da vida da sociedade. Foram utilizados vários instrumentos e políticas específicas e adequadas para que os Estadosmembros consigam implementá-las, promovendo uma mudança comportamental tanto da indústria quanto da sociedade e do Poder Público.

PALAVRAS CHAVE: Plásticos. União Europeia. Economia Circular.

\section{PLASTICS: THE WAY TO A MORE CIRCULAR ECONOMY}

\begin{abstract}
Although plastics have emerged as an economical solution, as they are cheaper, flexible, versatile and durable, in place of other products such as glass and steel, they have had a major negative impact on the environment and consequently on health. and human life through misuse and improper management of plastic waste. Faced with this problem, the European Union has formulated and approved some strategies so that this problem can be solved or at least mitigated its effects, without the need to remove all plastic products from the market and the life of society. Various specific and appropriate instruments and policies have been used for Member States to be able to implement them, promoting behavioral change in both industry, society and the government.
\end{abstract}

Keywords: Plastics. European Union. Circular Economy.

\footnotetext{
${ }^{1}$ Doutoranda em Direito Administrativo Iberoamericano, pela Universidade da Coruña, Espanha. Mestranda em Direito e Ciência Jurídica (Ciências Jurídico-Ambientais) pela Faculdade de Direito da Universidade de Lisboa. Graduada em Direito pela Universidade de Fortaleza (2009.1). Especialista em Direito Ambiental pela Universidade de Fortaleza (2011). Advogada inscrita na OAB/CE no 21.791. E-mail: jessicamtahim@hotmail.com.

2 Doutoranda em Direito Administrativo Iberoamericano, pela Universidade da Coruña, Espanha. Mestranda em Direito e Ciência Jurídica (Ciências Jurídico-Ambientais) pela Faculdade de Direito da Universidade de Lisboa. Possui graduação em Ciências Biológicas com ênfase em Biotecnologia pela Universidade do Vale do Itajaí (2008), graduação em Direito pela Universidade do Vale do Itajaí (2017). Pós-graduada em Gestão e Educação Ambiental pelo Centro Universitário Leonardo da Vinci (2012). Advogada em Itapema e região. E-mail: thaismuliterno@gmail.com.
} 


\section{INTRODUÇÃO}

No decorrer dos anos houve um aumento significativo na produção e consumo da população mundial, tornando-se insustentável para o Planeta, sendo considerada a mais ativa em toda a história dos seres humanos. O crescimento demográfico, a economia insustentável, a rápida urbanização e o aumento dos padrões de vida acabaram por diminuir ou até esgotar os recursos naturais, como, também, influenciam continuamente a geração de resíduos em todo o mundo, especialmente nos países em desenvolvimento (LIU; LIANG; SONG; LI, 2017, p. 1314).

E com a evolução industrial e tecnológica, o plástico foi criado sinteticamente para ser a solução econômica, por sua alta flexibilidade, versatilidade e durabilidade, sendo utilizados nos mais diversos produtos utilizados pelo homem, como em embalagens de alimentos, vestuário, veículos, material informático e eletrônicos, entre outros. Porém, diante dessa imensidão de utilidades para o plástico e da maior lucratividade com sua utilização, surgiram os problemas ambientais por seu mau uso pelo homem, como, também, por sua gestão e descarte indevidos.

Verdade seja que os principais impactos ambientais causados pela má gestão dos resíduos, especialmente os plásticos, são: a poluição marítima, contaminação as águas e o solo, por serem altamente tóxicas quando entram em decomposição, o que causa a contaminação de habitats terrestres, aquáticos e, principalmente, afeta a água doce (potável). Consequentemente, causa prejuízos à fauna e flora, à saúde e vida humana.

Diante desta problemática sobre o plástico, o que se buscou com o presente estudo foi analisar alguns dos benefícios e malefícios trazidos por sua utilização e, a partir disso, abordar as principais estratégias criadas pela União Europeia para solucionar esse problema, com um enfoque na estratégia da economia circular, que mesmo não sendo uma política recente, é muito eficaz para o que foi proposto, diante da sua relação com toda a cadeia produtiva, seja no desenvolvimento e produção, como, também, na distribuição e na gestão e eliminação final dos resíduos produzidos. Portanto, para um melhor entendimento sobre o tema, o presente estudo foi dividido da seguinte forma:

Primeiramente, um breve relato sobre o surgimento dos plásticos, como são utilizados na economia e a sua descoberta como uma solução econômica. E a partir dessa perspectiva, analisar os principais impactos causados ao ambiente e à saúde e vida humana.

Em continuidade, demonstrar como o caminho feito pela União Europeia para a transformação do seu sistema econômico, ao reconhecer os limites do Planeta, no tocante à 
escassez dos seus recursos e energia e da crise mundial que se apresentava, buscando o crescimento econômico equilibrado, com a promoção social e proteção do ambiente.

E nessa sua busca incessante pela sustentabilidade ambiental e percebendo a importância dos plásticos para a economia europeia e mundial, na última parte, serão demonstradas as novas estratégias europeias para se chegar à solução ou mitigação dos impactos negativos ocasionados pelo plástico, partindo para uma transformação econômica.

\section{PLÁSTICOS: DA SOLUÇÃO ECONÔMICA AO PROBLEMA AMBIENTAL}

O plástico já existia na natureza, antes mesmo de ser criado sinteticamente. As resinas existentes em algumas árvores conhecidas desde a antiguidade são consideradas plásticos naturais, como também havia o marfim, que podia ser moldado desde o século XVII. O plástico artificial foi criado a partir do avanço de vários inventores no decorrer dos anos. Tanto que "em 1870, o americano John Wesley Hyatt (1837-1920) produziu celulóide a partir da celulose das plantas", referida descoberta era para ser utilizada como substituição do marfim na fabricação das bolas de bilhar (REDAÇÃO MUNDO ESTRANHO, 2011).

No entanto, a "verdadeira revolução" foi em 1907, quando "o químico belga, naturalizado americano, Leo Baekeland (1863-1944) criou o primeiro plástico totalmente sintético e comercialmente viável, o Bakelite" (REDAÇÃO MUNDO ESTRANHO, 2011).

A palavra plástico vem do grego plastikos, na qual significa "próprio para ser moldado ou modelado". A grande maioria dos plásticos atualmente são produzidos de forma artificial, a partir de resinas derivadas do petróleo, ou seja, dependem totalmente dos combustíveis fósseis, e pertencem ao grupo dos polímeros, que são longas cadeias moleculares. Segundo estudiosos sobre o tema, existem tipos diferentes de plásticos que são determinados pela extensão e estrutura dos polímeros (ECYCLE). O termo plástico é aplicado a uma ampla gama de compostos orgânicos sintéticos, que são produzidos por polimerização, e estes consistem em muitas unidades repetidas (monômeros) que se juntam para criar copolímeros. A plasticidade dos plásticos permite que eles sejam pressionados ou extrudados em muitas formas diferentes (HAMMER; KRAAK; PARSONS, 2012, p. 02).

Após a revolução dos plásticos até os dias atuais, os plásticos são utilizados em quase tudo o que conhecemos, estando presente na maioria dos produtos que utilizamos diariamente, seja da cadeira ao automóvel, ou o notebook, roupas e calçados, ou ainda, protegendo ou mantendo os produtos frescos e limpos (PORTAL DA EDUCAÇÃO). Portanto, “o plástico é 
um material importante e omnipresente na economia e na vida quotidiana" (COMISSÃO EUROPEIA, 2018, p. 01).

Portanto, desde a década de 50, estamos vivendo a era dos plásticos, na qual se estima que 8.300 milhões de toneladas métricas de plásticos virgens tenham sido produzidos globalmente, tendo a produção global anual de plásticos aumentado vinte vezes desde a década de 1960, onde atingiu 322 milhões de toneladas em 2015, e a previsão é de dobrar novamente nos próximos 20 anos (WATKINS; SCHWEITZER, 2018, p. 04).

Convém destacar a importância da indústria dos plásticos para a economia europeia e mundial, sendo necessário, portanto, o reforço da sua sustentabilidade, no qual proporcionará novas oportunidades para a inovação, a competitividade e a criação de empregos, em consonância com os objetivos da estratégia para a política industrial da União Europeia (COMISSÃO EUROPEIA, 2018, p. 01).

O plástico, portanto, foi criado como uma solução socioeconômica a nível global, pois trata-se de "um material relativamente barato, durável e versátil". Os produtos criados a partir dos plásticos trouxeram vários benefícios para a sociedade, em termos de atividade econômica, empregos e qualidade de vida (EUROPEAN COMMISSION (DG ENVIRONMENT), 2011, p. 11). Porém, a má utilização dos plásticos pelo ser humano acabou por afetar o meio ambiente, a sustentabilidade e a saúde humana, causando vários impactos.

Esses problemas começaram apenas como um problema estético nas áreas urbanas, com o acúmulo de lixo nas cidades, campos, praias e até mesmo os oceanos, surgindo, logo em seguida, os problemas ambientais. Os inúmeros impactos negativos e potencialmente prejudiciais ao ambiente e ao humano por conta dos resíduos plásticos foram identificados, pois se percebeu que esses resíduos podem transportar poluentes orgânicos persistentes, toxidades, entre outros (BARNES; GALGANI; THOMPSON; BARLAZ, 2009, p. 1985).

Estudos afirmam que $85 \%$ do plástico produzido mundialmente não são reciclados e que muitos desses resíduos são descartados nos mares e oceanos, os quais acabam se fragmentando e, através das correntes marítimas, acabam por se encaminharem nas diversas partes do globo terrestre. Ainda não se tem relato sobre a dimensão do impacto dessa decomposição do plástico, que são chamadas de microplástico (INOUE; RIBEIRO, 2016, p. 02).

Como os plásticos são leves e duráveis, os resíduos plásticos se acumulam na superfície terrestre ou são, muitas vezes, transportados das áreas de origem para os sumidouros como o oceano. Estima-se que, aproximadamente, $49 \%$ de todos os plásticos produzidos são flutuantes, o que faz com que eles se desloquem através das correntes oceânicas para qualquer lugar do mundo (HAMMER; KRAAK; PARSONS, 2012, p. 05). 
Estudos constataram que, de acordo com suas estimativas a nível global, entre 4 e 12 milhões de metros de resíduos plásticos entraram no ambiente marinho em 2010, e que cerca de 150.000 a 500.000 toneladas de resíduos plásticos entram nos oceanos da UE anualmente. Portanto, os resíduos plásticos correspondem a cerca de $80 \%$ do lixo marinho, com $50 \%$ de lixo de praia composto por itens de plástico de uso único (SUP) (WATKINS; SCHWEITZER, 2018, p. 04).

Por conta da sua alta durabilidade, acaba por prolongar o seu tempo de decomposição e, consequentemente, acabam por formar grandes montes de lixo nos oceanos (LORENZETT; RIZZATTI; LORENZETT; GODOY, 2013, p. 2447). Ainda há mais um agravante, muitos produtos plásticos são considerados tóxicos, pois durante sua fabricação são colocados vários aditivos tóxicos tanto para o ambiente quanto à saúde humana (HAMMER; KRAAK; PARSONS, 2012, p. 05). O fato é que, quando esses resíduos plásticos se decompõem, acabam se transformando em petro-polímeros, que são substâncias altamente tóxicas, causando a contaminação das águas e do solo (WATKINS; SCHWEITZER, 2018, p. 05).

Portanto, por mais que os plásticos tenham se tornado desejáveis e muito importantes para a sociedade moderna, eles são letais para a fauna, pois inúmeras espécies de seres vivos são afetadas pela poluição por plástico, seja pelas redes de pescas deixadas nos oceanos ou por resíduos plásticos que são ingeridos por animais que confundem com alimento. Outro impacto negativo causado pela poluição por plástico é o transporte de espécies de uma região para outra, muitas delas exóticas que pegam carona nos resíduos e invadem novos ecossistemas, como, também, os contaminantes que são transferidos para o ambiente ou ingerido pelos animais (HAMMER; KRAAK; PARSONS, 2012, p. 19).

Além desses impactos, ainda há o consumo de combustíveis fósseis, matéria-prima utilizada na fabricação do plástico, o que acaba aumentando os gases de efeito estufa, que causam o aquecimento global.

Cumpre destacar que, diante de todos esses impactos causados ao ambiente pela poluição por plástico, mesmo o ser humano sendo um dos principais afetados, quanto a sua saúde, acaba sendo considerado como o vilão e a vítima, ao mesmo tempo.

\section{O CAMINHO PARA A TRANSFORMAÇÃO ECONÔMICA}

Quando há o reconhecimento dos limites do uso de recursos e energia planetária, percebe-se a importância de ver o mundo como um "sistema", no qual a poluição e o desperdício 
são vistos como uma derrota e, consequentemente, vê-se a necessidade de transformação da economia (BOCKEN; PAUW; BAKKER; GRINTEN, 2016, p. 308).

A União Europeia, por estar inserida na economia global de plásticos e por esse aumento vertiginoso dos problemas, tanto para o ambiente quanto à saúde humana, ciente dessa possibilidade do esgotamento dos recursos e diante da crise econômica que se apresenta mundialmente por conta da dependência humana direta a esses recursos, viu a necessidade de uma transformação econômica, sendo uma das pioneiras a lançar algumas estratégias, baseadas no desenvolvimento sustentável.

As principais medidas que vigoram acerca dessa transformação econômica, produção e consumo sustentáveis, como, também, os resíduos, atualmente na União Europeia, são: a Estratégia Europa 2020, o Plano de Ação da Economia Circular, a Estratégia para os Plásticos numa Economia Circular e a Diretiva recém aprovada sobre plásticos de uso único (SUP).

\subsection{ESTRATÉGIA EUROPA 2020}

Após a crise econômica, a União Europeia resolveu estabelecer estratégias a longo prazo para o período 2010-2020, composto por cinco objetivos principais, que cada Estado-Membro deveria enquadrar nos objetivos nacionais, quais sejam: emprego, investigação e inovação, alterações climáticas e energia, educação e luta contra a pobreza. O objetivo maior dessa estratégia é gerar um crescimento inteligente, sustentável e inclusivo.

A estratégia supracitada estabelece três prioridades que se reforçam mutuamente: 1) "Crescimento inteligente: desenvolver uma economia baseada no conhecimento e na inovação"; 2) "Crescimento sustentável: promover uma economia mais eficiente em termos de utilização dos recursos, mais ecológica e mais competitiva"; e 3) "Crescimento inclusivo: fomentar uma economia com níveis elevados de emprego que assegura a coesão social e territorial". Essas prioridades da União Europeia são representativas, ou seja, não são exaustivas, pois poderá haver um vasto leque de ações a nível nacional, da UE e internacional (COMISSÃO EUROPEIA, 2010, p. 05).

E para que tais objetivos sejam atingidos, foram estabelecidas duas iniciativas gerais: 1) Uma Europa eficiente em termos de recursos; e 2) Uma política industrial para a era da globalização. E cada uma dessa iniciativa tem suas estratégias próprias, mas sempre havendo uma interligação entre todas por conta do objetivo comum.

A Comissão Europeia o define como o crescimento através de uma economia 
sustentável, competitiva, na qual os recursos naturais sejam utilizados de forma eficiente. E para isso, deve-se investir no "desenvolvimento de novos processos e tecnologias, incluindo as tecnologias «verdes», acelerando a implantação das redes inteligentes que recorrem às TIC, explorando redes à escala da UE". Devendo-se, também, reforçar "as vantagens competitivas das nossas empresas, em especial a nível industrial e das PME, bem como através da prestação de assistência aos consumidores em matéria de utilização eficiente dos recursos" (COMISSÃO EUROPEIA, 2010, p. 17).

\subsection{PLANO DE AÇÃO DA ECONOMIA CIRCULAR}

Por muitos anos, viveu-se um modelo de economia linear, ou seja, baseado na extração, produção e eliminação. Verdade seja que, diante desse modelo econômico insustentável, viuse a necessidade de uma reformulação dessa economia, passando por uma economia verde e agora apostando na economia circular, na qual se foca na "preservação e valorização do capital natural e na minimização de desperdícios, centrando-se no "fecho do ciclo" em toda a cadeia de valor" (ECO.NOMIA).

Se a demanda por recursos naturais não for minorada, aumentará a produção de resíduos e as emissões geradas nas atividades de extração, processamento, consumo e descarte, além da deterioração resultante na qualidade ambiental. Diante desse fato, a transição para a economia circular é de extrema importância, pois além da impulsionar a proteção do ambiente, através da utilização racional dos recursos, diminuição da poluição, entre outros, haverá uma melhora econômica. O que acaba se tornando, também, um grande impulsionador da reindustrialização, criação de empregos e crescimento econômico, através das novas oportunidades que surgirão em vários setores, incluindo a produção de materiais secundários, reparos e remanufatura, o setor de serviços e a economia de compartilhamento (MCCARTHY; DELLINK; BIBAS, 2018, p. 12).

No entendimento de STAHEL (2016, p. 436), a "economia circular é como um lago", no qual o "reprocessamento de bens e materiais gera empregos e economiza energia, reduzindo o consumo de recursos e o desperdício". Como, por exemplo, limpar uma garrafa de vidro e usá-la novamente é mais rápido e barato do que reciclar o vidro ou fazer uma nova garrafa a partir de minerais e os pneus usados dos veículos, em vez de serem despejados, são coletados pelos gerentes de resíduos e vendidos ao maior lance.

Convém destacar que a transição para uma Economia Circular se baseia principalmente 
em uma ação conjunta de todos os atores da cadeia de valor, ou seja, a participação desde os produtores aos consumidores, assentando em I\&I (política de Investigação e Inovação) com base numa abordagem sistêmica, multidisciplinar, colaborativa e de ecodesign de soluções como alavanca para a mudança (FUNDAÇÃO PARA A CIÊNCIA E TECNOLOGIA (FCT), 2017).

A União Europeia, nos últimos anos, concentrou suas estratégias no desenvolvimento de políticas que abordassem especificamente algumas das questões problemáticas em torno dos plásticos. Portanto, já em 2015, ao fazer o Plano de Ação da UE para uma Economia Circular, buscou incluir a problemática dos plásticos, reforçando a competitividade e a promoção do tão almejado desenvolvimento sustentável.

\section{INTRODUÇÃO}

O Brasil, segundo dados divulgados no ano de 2019 pelo Programa das Nações Unidas para o Desenvolvimento (Pnud), se classifica como o sétimo país mais desigual do mundo, ficando atrás somente de países do continente africano. De acordo com o relatório da Organização das Nações Unidas (ONU), o Brasil ocupa o segundo lugar no ranking das maiores concentrações de renda nas mãos de poucas pessoas, uma vez que $28 \%$ de toda a riqueza encontra-se de posse de apenas $1 \%$ da população.

\section{NA BUSCA DE NOVOS RUMOS PARA O PLÁSTICO NA EUROPA}

Diante da notória necessidade de mudança e da problemática global com os resíduos plásticos, a União Europeia resolveu criar estratégias específicas e, pode-se dizer, drásticas com relação à gestão dos produtos e resíduos plásticos, influenciando em toda a cadeia produtiva, consumo e pós-consumo.

\subsection{ESTRATÉGIA PARA OS PLÁSTICOS NUMA ECONOMIA CIRCULAR}

As soluções para os plásticos baseadas numa economia circular devem se concentrar na eliminação de plásticos de uso único e no gerenciamento eficaz de plásticos duradouros, como os usados em veículos e na construção (UNITED NATIONS DEVELOPMENT PROGRAMME, 2019, p. 10).

A União Europeia se encontra em uma posição privilegiada e de liderança na Ponto de Vista Jurídico | Caçador | v.10 | nº 1 | p. 91 - 109 | jan./jul. 2021 
transformação econômica para o futuro dos plásticos, através da nova Estratégia para os Plásticos numa Economia Circular ${ }^{3}$, aprovada em janeiro de 2018, na qual se estabelece as "bases para uma nova economia do plástico, em que a concepção e produção de plásticos e de produtos de plástico respeitem plenamente as necessidades de reutilização, reparação e reciclagem e que desenvolva e promova materiais mais sustentáveis" (COMISSÃO EUROPEIA, 2018, p. 01).

Prevê-se, portanto, o investimento em inovação e novas tecnologias para a solução dos problemas com o consumo de plásticos e, consequentemente, reduzir a poluição pelo plástico e seu o impacto negativo na saúde humana e no ambiente. Sendo, portanto, o maior objetivo da referida estratégia a implementação de uma "economia moderna, hipocarbônica, eficiente em termos de energia e recursos, bem como, de forma tangível, para a consecução dos objetivos de desenvolvimento sustentável para 2030 e do Acordo de Paris" (COMISSÃO EUROPEIA, 2018, p. 01).

É sobremodo importante assinalar que, seis organizações europeias (Plastics Recyclers Europe (PRE), Petcore Europe, European Carpet and Rug Association (ECRA), Polyolefin Circular Economy Platform (PCEP Europe), European Plastics Converters (EuPC) e VinylPlus), em conjunto com a Comissão Europeia, adotaram um quadro de compromissos voluntários com o objetivo global de até 2040 atingir a reciclagem a um nível de $50 \%$ no que tange aos resíduos plásticos, portanto, prosseguir e expandir as atuais atividades de reciclagem de plásticos (COMISSÃO EUROPEIA, 2018, p. 08).

Ademais, o papel da Comissão é apoiar os municípios, para que evitem resíduos de plástico e poluição, devendo, também, reconhecer o papel dos cidadãos nessa jornada para uma economia sustentável de plásticos, incluindo o apoio à inovação do setor privado.

Na aprovação do Pacote de Economia Circular de 2015, inclui-se uma proposta de alteração da Diretiva Embalagens e Resíduos de Embalagens, na qual inclui os seus objetivos de reciclagem. Então, em maio de 2018, foi aprovada a Diretiva 2018/852, que definiu metas de reciclagem de embalagens plásticas de $50 \%$ em peso até 2025 e $55 \%$ em peso até 2030 .

\footnotetext{
${ }^{3}$ Os objetivos da referida estratégia são: 1) "Todas as embalagens plásticas na UE devem poder ser reutilizadas ou recicladas de forma rentável até 2030 '; 2) "Reciclagem de mais de $50 \%$ dos resíduos de plástico gerados na Europa até 2030 "; 3 ) "Aumento de quatro vezes na capacidade de triagem e reciclagem e melhoria da coleta seletiva até 2030"; 4) "Aumento de quatro vezes na demanda por plásticos reciclados, apoiada por um mercado estabelecido"; 5) "Maior uso de materiais inovadores e matérias-primas alternativas (ou seja, não fósseis) para a produção de plásticos, onde eles são comprovadamente mais sustentáveis"; 6) 'Maior uso de soluções circulares para promover a prevenção de resíduos plásticos, como a reversão logística para embalagens e alternativas para plásticos descartáveis"; 7) "Uma diminuição "drástica" do vazamento de plásticos para o meio ambiente"; e 8) "Um papel de liderança para a UE no contexto global de tratamento de resíduos de plástico e poluição". (WATKINS; SCHWEITZER, 2018, p. 07).
} 
Referida diretiva trouxe metas mais ambiciosas do que a anterior de alcançar 22,5\% até 2008 (WATKINS; SCHWEITZER, 2018, p. 08).

Os Estados-membros terão de elaborar políticas nacionais sólidas para atingir os novos objetivos municipais de reciclagem de resíduos (55\% até 2025, 0\% até 2030 e 65\% até 2035), metas globais de reciclagem de embalagens (65\% até 2025 e 70\% até 2030), e metas de reciclagem de embalagens plásticas (50\% até 2025 e 55\% até 2030). Isso será fiscalizado e acompanhado pela Comissão Europeia, juntamente com relatórios regulares sobre as realizações objetivos da Estratégia de Plásticos (WATKINS; SCHWEITZER, 2018, p. 15).

Diante do exposto, para que a proposta da Economia Circular seja realmente efetiva, faz-se necessária a observância de algumas fases do ciclo de vida do produto.

\subsubsection{Ciclo de vida do produto}

O ciclo de vida de um produto começa com a própria Terra, que fornece uma riqueza de recursos, sejam eles renováveis ou não, como, também, as fontes de energia. Após a extração desses recursos, eles entram nas cadeias de produção e fornecimentos de produtos ou podem ser usados na produção de energia. E através do design e fabricação de produtos, esses recursos, agora transformados em matéria-prima, são processados para criar produtos e serviços, que atendam às necessidades da sociedade. Ao final de suas vidas, a maioria dos produtos é coletada e reutilizada, processada para retornar ao uso ou descartada como resíduo (U.S. ENVIRONMENTAL PROTECTION AGENCY, 2009, p. 04).

Os produtos, ao longo do seu ciclo de vida, acabam gerando impactos ao ambiente, seja na extração e processamento de matérias-primas; durante a fabricação, montagem e distribuição; devido à sua embalagem, uso e manutenção; e/ou no final de sua vida (FITZGERALD; HERRMANN; SANDBORN; SCHMIDT; GOGOLL, 2007).

E ainda há um agravante, pois cada etapa desse ciclo requer a utilização de energia e água como insumos, causando impactos ambientais no ar, na água e na terra. Além do fato de que, no decorrer de todo o fluxo de materiais e produtos, requerem transporte e distribuição, contribuindo ainda mais para os impactos ambientais, sejam globais, nacionais ou locais (U.S. ENVIRONMENTAL PROTECTION AGENCY, 2009, p. 04).

A análise do ciclo de vida de um produto é considerada "uma ferramenta de gestão criada para computar entradas e saídas de um sistema de produção, com o objetivo de avaliar o desempenho ambiental dos produtos durante as diversas etapas do seu ciclo de vida". Essa 
análise é muito conhecida como "craddle-to-grave analysis", ou seja, análise do berço à túmulo (COELHO FILHO; SACCARO JUNIOR; LUEDEMANN, 2016, p. 07).

Cumpre destacara que as etapas para a fabricação de um produto são: 1) Concepção/design do produto; 2) Processo de produção; 3) Distribuição; 4) Utilização; 5) Gestão dos resíduos ou eliminação (ECO.NOMIA). Portanto, deve-se fazer uma análise de todo esse ciclo, preocupando-se com toda a cadeia de valor, fazendo-se necessária uma melhor análise de algumas dessas etapas.

\subsubsection{A importância do ecodesign para todo o ciclo de vida do produto}

O termo ecodesign se refere às ações no desenvolvimento de produtos, com o objetivo de minimizar o impacto ambiental durante todo o seu ciclo de vida, sem comprometer outros critérios essenciais do produto, como desempenho e custo (JOHANSSON, 2002, p. 98).

O design e desenvolvimento de novos produtos, processos e serviços, através da estratégia de investigação e inovação, "visa contribuir significativamente para uma maior circularidade da economia, promovendo modelos de produção e consumo mais sustentáveis a nível ambiental, social e económico, com base numa perspectiva de ciclo de vida". Esse novo desenvolvimento de produtos deve incluir o "fecho dos ciclos biológico e tecnológico de materiais, a extensão do tempo de vida dos produtos e o desenvolvimento de novos fluxos, materiais, processos e serviços mais eficientes e com baixas pegadas ecológicas e a implementação de uma economia de partilha e de desempenho" (FUNDAÇÃO PARA A CIÊNCIA E TECNOLOGIA (FCT), 2017, p. 02).

Com o desenho de produtos e serviços projetados para vários ciclos de vida, economicamente viáveis e ecologicamente eficientes. Desenho ou redesenho de produtos de concepção mais duradoura e utilizando menos recursos (ECO.NOMIA).

Portanto, na fase de desenvolvimento do produto é onde se é possível saber quais impactos aquele produto vai acarretar sobre todo o seu ciclo de vida, pois é nessa fase são determinadas as matérias primas a serem usadas, o processo de produção, a distribuição e transporte, a utilização e a reciclagem, até a eliminação (CASTRO, 2011, p. 02), ou seja, o produto é desenhado com uma concepção mais duradoura e utilizando menos recursos ou material reciclado.

Um exemplo de desenvolvimento de novos produtos em substituição do plástico é o Solanyl, que é um polímero produzido pela Rodenburg Biopolymers, cujas características são 
semelhantes aos plásticos utilizados na engenharia, como o polietileno, polipropileno e poliestireno. Referido produto utiliza $65 \%$ menos energia para ser fabricado e é 10 a $50 \%$ mais barato em comparação aos citados polímeros sintéticos (BOCKEN; PAUW; BAKKER; GRINTEN, 2016, p. 315-316).

Esse produto é fabricado principalmente através das cascas de batata que sobraram da produção de batatas fritas e outros produtos de batata permitem o preço mais baixo. Tem alta capacidade biodegradação no solo e pode ser usado como nutriente por microrganismos. Sendo, portanto, considerado uma forma sustentável de substituição do plástico (BOCKEN; PAUW; BAKKER; GRINTEN, 2016, p. 315-316).

Outra iniciativa positiva quanto a isso é a CBPAK, que "está unindo ciência material e inovação em modelo de negócio para gerar valor a partir da mandioca", ou seja, referida empresa utiliza a mandioca brava, uma espécie não comestível, na produção de embalagens descartáveis, em substituição aos "problemáticos plásticos". A proposta da empresa é fazer a logística reversa com seus clientes, que farão o descarte das embalagens pós-uso, e através de parceiras com "empresas locais de compostagem, que coletam as embalagens usadas e as convertem em adubo que pode ser usado para regenerar terras agrícolas" (CHAVIN, 2017, p. $02)$.

Pelo exposto, nota-se que ao desenvolver produtos mais sustentáveis, serão adotados processos de produção mais limpos, limitando a utilização de substâncias tóxicas, ainda promover a utilização racional dos recursos, sejam de materiais, energia ou recursos hídricos.

\subsubsection{Gestão de resíduos e a importância da logística reversa nessa fase}

Como já mencionado anteriormente, diante do aumento da produção de resíduos pela população, do consumo desenfreado e do alto custo no tratamento e gestão dos resíduos sólidos, e com o surgimento de legislações mais restritivas e preocupadas com a proteção ambiental, fizeram com que os Estados repensassem a forma como essa gestão era feita, procurando cada vez mais alternativas mais sustentáveis para o tratamento e descartes de resíduos sólidos (MARQUES; AGUIAR, 2004, p. 846).

A Estratégia Europeia para Plásticos em uma Economia Circular de 2018 observou que a reciclagem de plástico não acompanhou a sua crescente produção global. Atualmente, na Europa, apenas 30\% dos resíduos plásticos são coletados para reciclagem e, na sua maioria, essas operações de reciclagem ocorre fora da Europa, onde as práticas e padrões ambientais 
podem ser diferentes (EUROPEAN ENVIRONMENT AGENCY, 2019, p. 22).

Portanto, percebe-se que com a economia linear, após a utilização do produto, ele era eliminado em aterros sanitários ou lixões, que muitas vezes não tinham o tratamento correto e acabava ocasionando a poluição do ambiente. Com essa mudança de paradigma para uma economia mais circular, esse resíduo se transforma novamente em recurso, ou seja, acontece a sua reentrada no ciclo de produção, e o que era resíduo é utilizado na cadeia produtiva como recurso, matéria-prima.

Essa reutilização, remanufatura ou reciclagem pode ser feita de duas formas, através do upcycling, que significa a "reutilização criativa, processo de reconversão de resíduos em novos materiais ou produtos de maior valor acrescentado" ou do downcycling, que é o "processo de reconversão de resíduos em novos materiais ou produtos de menor qualidade/funcionalidade reduzida" (ECO.NOMIA).

Verdade seja que a logística reversa ${ }^{4}$ é uma obrigação das empresas de coleta dos resíduos provenientes do consumo de seus produtos para serem recuperados, reutilizados ou reciclados. É considerada umas das responsabilidades por parte do produtor no ciclo de vida do produto e depende da estratégia escolhida pelo Estado, através de sua legislação nacional, que geralmente é feita uma parceria entre o Poder Público e o particular, para que possa ser feita a retirada do produto ou resíduo após sua utilização.

\subsection{DIRETIVA PARA A REDUÇÃO DO IMPACTO DE DETERMINADOS}

\section{PRODUTOS DE PLÁSTICO NO AMBIENTE}

Em maio de 2018, a Comissão Europeia elaborou uma proposta legislativa sobre os chamados plásticos de uso único (SUP), entre outros 5 , com o objetivo maior de reduzir o impacto ambiental e sanitário dos produtos de plástico e a promoção da transição para uma economia circular. A adoção da proposta foi votada e aprovada pelo Parlamento Europeu em 24 de outubro de 2018, relativa à redução do impacto de determinados produtos de plástico no ambiente, com alterações (WATKINS; SCHWEITZER, 2018, p. 07).

\footnotetext{
${ }^{4}$ É definida como um "instrumento de desenvolvimento econômico e social caracterizado por um conjunto de ações, procedimentos e meios destinados a viabilizar a coleta e a restituição dos resíduos sólidos ao setor empresarial, para reaproveitamento, em seu ciclo ou em outros ciclos produtivos, ou outra destinação final ambientalmente adequada". Art. $3^{\circ}$, XII, da Lei $\mathrm{n}^{\circ}$. 12.305, de 02/08/2010. Disponível em: <http://www.planalto.gov.br/ccivil_03/_ato2007-2010/2010/lei/112305.htm>. Acesso em: 09/08/2019.

${ }^{5}$ Os plásticos de Uso Único (SUPs) são os mais frequentemente encontrados como lixo nas praias da UE, juntamente com artes de pesca.
} 
Referida proposta foi aprovada e transformou-se em Diretiva, em 05 de junho de 2019, e tem como principais objetivos: 1) "prevenir e reduzir o impacto de determinados produtos de plástico no ambiente, mais particularmente no meio aquático, e na saúde humana"; e 2) "promover a transição para uma economia circular com modelos de negócio, produtos e materiais inovadores e sustentáveis, contribuindo assim igualmente para o funcionamento eficiente do mercado interno" (PARLAMENTO EUROPEU E DO CONSELHO, 2019).

Os produtos de plásticos de utilização única foram definidos pela Diretiva, para uma melhor aplicação pelos Estados-membros, no seu artigo $3^{\circ}$, item 2, como:

Um produto fabricado total ou parcialmente a partir de plástico e que não é concebido, projetado ou colocado no mercado para perfazer múltiplas viagens ou rotações no seu ciclo de vida mediante a sua devolução a um produtor para reenchimento ou a sua reutilização para o mesmo fim para o qual foi concebido (PARLAMENTO EUROPEU E DO CONSELHO, 2019).

Além dos plásticos de utilização única, os quais foram enumerados pela Diretiva, a União Europeia incluiu os produtos feitos de plástico oxodegradável e às artes de pesca que contêm plástico.

Para tanto, cumpre destacar que referida transformação econômica não está e nem será fácil, pois existem vários desafios a serem enfrentados, tais como o "desenvolvimento e adoção de processos de produção mais eficientes", e "a alteração de comportamentos, o desenvolvimento e teste de tecnologias e materiais renováveis (sempre que possível), a exploração sustentável de matérias-primas essenciais" (FUNDAÇÃO PARA A CIÊNCIA E TECNOLOGIA (FCT), 2017).

Para que a transformação aconteça é necessário o investimento dos Estados-membros em novas tecnologias e inovação, que poderá ser feito através de incentivos fiscais e políticas públicas modeladora de comportamento, seja por parte da sociedade ou das empresas particulares e do próprio Estado, através de políticas que facilitem a circulação de bens e serviços e da economia como um todo.

\section{CONCLUSÃO}

É inequívoca a importância dos plásticos na economia mundial, em especial na Europa, pois sua utilização está nos mais diversos produtos, por conta do seu baixo custo, sua versatilidade e durabilidade. No entanto, diante da sua má utilização pelos seres humanos, acabaram por causar vários impactos e danos ao ambiente e à própria saúde e vida humana. 
No que se refere aos impactos ambientais decorrentes do mau uso desses produtos, destacamos: contaminação das águas, principalmente a água potável, também chamada de doce, e do solo por causa das substâncias tóxicas liberadas na decomposição do plástico, o que acaba prejudicando diversos habitats terrestres e aquáticos. E ainda há um dos maiores problemas da atualidade, que é a poluição marinha, pois não há limites nos mares e oceanos, eles são interligados, então, quando há um descarte de lixo em uma determinada região, ele percorre através das correntes marítimas até outro continente. Além dos impactos e prejuízos ambientais, por se tratar de um sistema, onde tudo está interligado, consequentemente, acaba afetando a fauna e flora, como, também à saúde e vida humana.

Oportuno destacar que a União Europeia, ciente da crise mundial que assola os países, da escassez de recursos naturais e da importância econômica dos plásticos e dos efeitos negativos causados pela utilização predatória dos recursos naturais e da má gestão dos resíduos, mostrou-se pioneira em buscar soluções para que seus Estados-membros consigam melhor gerir o desenvolvimento econômico, sempre buscando a sustentabilidade ambiental e social.

Diante dessa percepção sobre os novos rumos para a Europa, foram estabelecidas estratégias pontuais para solucionar o problema dos plásticos, que são: Estratégia para os plásticos numa Economia Circular e a Diretiva para a redução do impacto de determinados produtos de plástico no ambiente. São ações novas, com o intuito de trazer uma mudança radical no que concerne a economia do plástico, passando a incluí-los na Economia Circular já existente, porém, com as adaptações devidas.

É importante ressaltar que a Economia Circular é considerada uma estratégia econômica baseada na "redução, reutilização, recuperação e reciclagem de materiais e energia potenciando o valor e, consequentemente, o tempo de vida útil dos produtos, materiais e recursos na economia", visando a "valorização dos recursos, principalmente os renováveis e recicláveis, através do conhecimento aprofundado dos processos tecnológicos, sociais, ambientais, culturais e económicos associados ao metabolismo da economia" (FUNDAÇÃO PARA A CIÊNCIA E TECNOLOGIA (FCT), 2017).

De acordo com estudo da OCDE, a reciclagem, a nível global, tem um mercado estimado entre 700 e 800 mil toneladas e avaliado no valor de mais de 200 bilhões de dólares. Dentre os principais materiais comercializados estão os metais, papel e plástico (OECD GREEN GROWTH STUDIES, 2015, p. 93). Isso mostra como a reciclagem tem um grande potencial de investimento econômico.

Contudo, somente a reciclagem não é suficiente para a mudança esperada e é isso que a nova estratégia dos plásticos na economia circular traz, na qual há uma maior preocupação com 
o ciclo de vida do plástico, na prevenção da produção de resíduos, buscando uma alteração comportamental da sociedade como um todo, na qual haja uma redução no consumo dos produtos plásticos ou até a substituição destes.

Portanto, buscou-se promover a diminuição da sua utilização de produtos plásticos, através do investimento em investigação e inovação de novos produtos que pudessem substituir, promover uma transformação comportamental da sociedade, fazendo com que repensasse os atuais padrões de consumo e produção de resíduos. Como, também, através da economia circular, fazer com que os resíduos se transformem em recursos e retornem a cadeia produtiva, diminuindo, assim, o seu descarte.

Apesar do alto nível de interesse público em resíduos plásticos e seus graves impactos no meio ambiente e, consequentemente, na saúde humana, a geração de resíduos plásticos ainda está aumentando e continuará a acontecer. Portanto, a prevenção dos resíduos de plástico na fonte se mostra a estratégia mais eficaz, tendo particularmente em conta os investimentos necessários em instalações de tratamento de resíduos de fim de linha e infraestruturas que seriam necessárias para lidar com estas quantidades crescentes de resíduos de plástico (EUROPEAN ENVIRONMENT AGENCY, 2019, p. 31).

Diante do exposto, tratam-se de estratégias novas para resolver os problemas dos plásticos, estando ainda em implementação pelos Estados-membros, porém, pode-se ver que já está acontecendo uma mudança de postura da sociedade e dos Estados, na qual já existem acordos voluntários de industrias interessadas no investimento de novas soluções, em parceria com o Poder Público, através de incentivos econômicos. Tudo isso possibilitará uma melhor gestão dos recursos, evitando desperdícios, sendo, portanto, um instrumento de extrema importância para cumprir os compromissos climáticos em nível nacional.

\section{REFERÊNCIAS}

BARNES, David K. A.; GALGANI, Francois; THOMPSON, Richard C.; e BARLAZ, Morton. Accumulation and fragmentation of plastic debris in global environments. $\mathrm{N}^{\circ}$. 364. 2009. Phil. Trans. R. Soc. B. P. 1985-1998. Disponível em: <http://doi.org/10.1098/rstb.2008.0205>. Acesso em: 27 abr. 2020.

BOCKEN, Nancy M. P.; PAUW, Ingrid de; BAKKER, Conny; e GRINTEN, Bram van der. "Product design and business model strategies for a circular economy". In: Journal of Industrial and Production Engineering. 33:5. 26 Apr 2016. Disponível em: <https://doi.org/10.1080/21681015.2016.1172124>. Acesso em: 02 maio 2019.

CASTRO, Filipa Gonçalves de. Integração de Práticas de Ecodesign no Processo de 
Desenvolvimento de Novos Produtos. Tese de Mestrado Engenharia Industrial/Gestão Industrial. Universidade do Minho. Jul. 2011.

CHAVIN, Stella; e JEFFRIES, Nick. Six circular economy case studies from Brazil. 2017. Disponível em: <https://medium.com/circulatenews/six-circular-economy-case-studies-frombrazil-3d7a9656da26>. Acesso em: 10 mar. 2021.

COELHO FILHO, Osmar; SACCARO JUNIOR, Nilo Luiz; LUEDEMANN, Gustavo. “A avaliação de ciclo de vida como ferramenta para a formulação de políticas públicas no Brasil”. In: Texto para discussão. Brasília: IPEA, 2016.

COMISSÃO EUROPEIA. "Nova estratégia ambiciosa para promover os plásticos". In: Revista Ambiente para os Europeus. 16/03/2018. Disponível em: $<$ https://ec.europa.eu/environment/efe/themes/economics-strategy-and-information/ambitiousnew-strategy-make-plastic-fantastic_pt>. Acesso em: 13 maio 2019.

COMISSÃO EUROPEIA. “Uma Estratégia Europeia para os Plásticos na Economia Circular". In: Comunicação da comissão ao parlamento europeu, ao conselho, ao comité económico e social europeu e ao comité das regiões. COM (2018) 28 final. Estrasburgo, 16 jan. 2018.

COMISSÃO EUROPEIA. Europa 2020-Estratégia para um crescimento inteligente, sustentável e inclusivo (COM (2010) 2020 final. Bruxelas, 03 mar. 2010. Disponível em: $<$ http://www.pocicompete2020.pt/admin/fileman/Uploads/Documents/Estrategia_europa2020.pdf >. Acesso em: 01 maio 2019.

ECO.NOMIA. Economia Circular - Estratégias da Economia Circular. Disponível em: <http://eco.nomia.pt/pt/economia-circular/diagrama-de-sistemas〉. Acesso em: 29 abr. 2019.

ECYCLE. De onde vêm e o que são os plásticos? Disponível em: $<$ https://www.ecycle.com.br/component/content/article/35-atitude/676-de-onde-vem-e-o-quesao-os-plasticos.html>. Acesso em: 27 abr. 2019.

EUROPEAN COMMISSION (DG ENVIRONMENT). Plastic Waste in The EnvironmentFinal Report. April 2011. Disponível em:

<http://ec.europa.eu/environment/waste/studies/pdf/plastics.pdf>. Acesso em: 02 maio 2019.

EUROPEAN ENVIRONMENT AGENCY. Preventing plastic waste in Europe. EEA Report, $n^{\circ}$. 02/2019. Disponível em: <https://www.eea.europa.eu/publications/preventingplastic-waste-in-europe>. Acesso em: 14 ago. 2019.

FITZGERALD, Daniel P.; HERRMANN, Jeffrey William; SANDBORN, Peter A.; SCHMIDT, Linda C. e GOGOLL, Thornton H. Design for Environment (DfE): Strategies, Practices, Guidelines, Methods, and Tools. March 2007. Disponível em: <https://onlinelibrary.wiley.com/doi/10.1002/9780470168202.ch1>. Acesso em: 02 ago. 2019.

FUNDAÇÃO PARA A CIÊNCIA E TECNOLOGIA (FCT). Extrato do Plano Nacional de Ciência e Tecnologia (PNCT). Julho 2017. Disponível em: 
$\langle$ https://www.fct.pt/agendastematicas/docs/inclusao_social_e_cidadania.pdf $>$. Acesso em: 20 dez. 2018.

HAMMER, Jort; KRAAK, Michiel H.S.; e PARSONS, John R. "Plastics in the Marine Environment: The Dark Side of a Modern Gift". In: Reviews of Environmental Contamination and Toxicology. D.M. Whitacre, 2012. Disponível em:

<https://www.ncbi.nlm.nih.gov/pubmed/22610295>. Acesso em: 27 abr. 2019.

INOUE, Cristina Y. A.; RIBEIRO, Thais Maria Machado Lemos. Padrões sustentáveis de produção e consumo: resíduos sólidos e os desafios de governança do global ao local. Meridiano 47, 17: e17008, 2016. Disponível em:

<https://www.researchgate.net/publication/299496666_Padroes_sustentaveis_de_producao_e _consumo_residuos_solidos_e_os_desafios_de_governanca_do_global_ao_local>. Acesso em: 14 jun. 2019.

JOHANSSON, Glenn. "Success factors for integration of ecodesign in product development A review of state of the art". In: Environmental Management and Health. Vol. 13, $\mathrm{n}^{\mathrm{o}} .1$, 2002.

LIU, Lili; LIANG, Yangyang; SONG, Qingbin; e LI, Jinhui. "A review of waste prevention through 3R under the concept of circular economy in China". In: J Mater Cycles Waste Manag. 2017. Disponível em:

$<$ https://www.researchgate.net/publication/316009473_A_review_of_waste_prevention_throu gh_3R_under_the_concept_of_circular_economy_in_China>. Acesso em: 16 mar. 2019.

LORENZETT, Juliana Benitti; RIZZATTI, Cláudia Bach; LORENZETT, Daniel Benitti; GODOY, Leoni Pentiado. "Sacolas plásticas: uma questão de mudança de hábitos".

In:LORENZETT et al. $\mathrm{n}^{\circ}$ 11. P. 2446-2454, jan-abr 2013. Disponível em:

<https://periodicos.ufsm.br/index.php/remoa/article/view/7725>. Acesso em: 27 abr. 2020.

MARQUES, Claudia Scoton Antonio; e AGUIAR, Edson Martins de. A importância da logística reversa no gerenciamento de resíduos sólidos. Florianópolis: ICTR, 2004. Disponível em: <https://www.ipen.br/biblioteca/cd/ictr/2004/ARQUIVOS\%20PDF/06/06071.pdf>. Acesso em: 09 ago. 2019.

MCCARTHY, Andrew; DELLINK, Rob; e BIBAS, Ruben. "The Macroeconomics of the Circular Economy Transition: A Critical Review of Modelling Approaches". In: OECD Environment Working Papers. N ${ }^{\circ}$. 130. Paris: OECD Publishing, 2018. Disponível em: <http://dx.doi.org/10.1787/af983f9a-en>. Acesso em: 05 ago. 2019.

OECD GREEN GROWTH STUDIES. Material Resources, Productivity and the Environment. 12 Feb. 2015. Disponível em: <https://www.oecdilibrary.org/docserver/9789264190504en.pdf?expires $=1560776464 \& \mathrm{id}=\mathrm{id} \&$ accname $=$ ocid54022976 $\&$ checksum $=38 \mathrm{~B} 453803 \mathrm{C} 9 \mathrm{BA}$ 55BCB9F2277BB9EA16A>. Acesso em: 17 jun. 2019.

PARLAMENTO EUROPEU E DO CONSELHO. Diretiva (UE) 2019/904. 5 de junho de 2019. Relativa à redução do impacto de determinados produtos de plástico no ambiente. Disponível em: <https://apambiente.pt/_zdata/Politicas/Residuos/Plastico_de_UsoUnico/Diretiva_SUP_PT.pd 
f>. Acesso em: 08 ago. 2019.

PORTAL DA EDUCAÇÃO. Sacolas Plásticas x Meio Ambiente: Como re(agir)?

Disponível em:

$<$ https://www.portaleducacao.com.br/conteudo/artigos/conteudo/sacolas/14622\#ixzz2IFMeC Qf4>. Acesso em: 27 abr. 2019.

REDAÇÃO MUNDO ESTRANHO. “Como foi inventado o plástico?”. In: Revista Super Interessante. Publicado em 18/04/2011. Disponível em: <https://super.abril.com.br/mundoestranho/como-foi-inventado-o-plastico/>. Acesso em: 26 abr. 2019.

STAHEL, Walter R. “The circular economy”. In: Comment-Nature. Vol. 531. 24/03/2016. Disponível em:

<https://www.nature.com/news/polopoly_fs/1.19594!/menu/main/topColumns/topLeftColum n/pdf/531435a.pdf>. Acesso em: 30 abr. 2019.

\section{U.S. ENVIRONMENTAL PROTECTION AGENCY. Sustainable Materials Management:} The Road Ahead. June 2009. Disponível em: $<$ https://www.epa.gov/sites/production/files/201508/documents/sustainable_materials_management_the_road_ahead.pdf $>$. Acesso em: 06 ago. 2020.

UNITED NATIONS DEVELOPMENT PROGRAMME. Plastics and Circular Economy: Community Solutions. 2019. Disponível em:

$<$ https://www.thegef.org/sites/default/files/publications/gef_sgp_plastics_circular_economy_p ub_june2019.pdf>. Acesso em: 17 jul. 2019.

WATKINS, Emma e SCHWEITZER, Jean-Pierre. "Moving towards a circular economy for plastics in the EU by 2030". In: Think 2030. 12 October 2018. Disponível em: $<$ https://ieep.eu/uploads/articles/attachments/4e8d42a2-c8a8-4d40-bae0c3429b10fe4d/Think\%202030\%20Circular\%20economy\%20for\%20plastics.pdf?v=63710011 292>. Acesso em: 26 abr. 2019. 